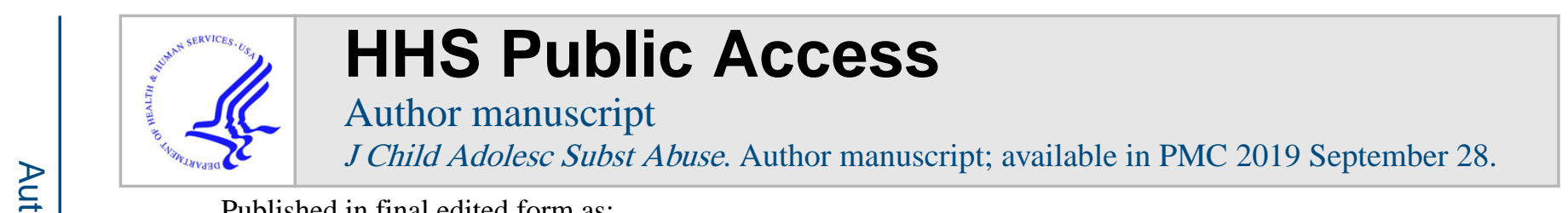

Published in final edited form as:

J Child Adolesc Subst Abuse. 2018 ; 27(5-6): 288-296. doi:10.1080/1067828X.2018.1500964.

\title{
Risk Factors for Substance Use Among Youth Experiencing Homelessness
}

\author{
Marguerita Lightfoot, PhD, \\ UCSF Division of Prevention Science \\ Nancy Wu, MD, \\ Pacific Asian Counseling Services \\ Shana Hughes, PhD, MPH, \\ UCSF Division of Prevention Science \\ Kate Desmond, MS, \\ UCLA Luskin School of Public Affairs
}

Heather Tevendale, PhD, Robin Stevens, PhD, MPH

University of Pennsylvania School of Nursing

\section{Abstract}

Background-Youth experiencing homelessness are at high risk for frequent substance use. This study examines individual, interpersonal, and contextual factors associated with substance use among such youth, age 13-24.

Methods-Data were collected through computer-assisted structured interviews with participants $(\mathrm{N}=474)$ recruited at service agencies in Los Angeles.

Results-Youth had experienced over two years of homelessness on average. Almost a third used substances frequently; significant risk factors included delinquency, sensation seeking, and ongoing homelessness. Time spent in clubs and organizations was protective.

Conclusions-Providing housing and services to curb delinquency may help protect youth from becoming frequent substance users.

\section{Keywords}

Homeless; Substance Use; Protective Factors; Risk Factors

\section{Risk factors for substance use among youth experiencing homelessness}

Youth experiencing homelessness and unstable housing (hereafter, YEH) engage in particularly high rates of substance use. Multiple national and small-scale studies have found that 66-97\% of YEH use alcohol, drugs or both (Zerger, Strehlow and Gundlapalli 2008; Salomonsen-Sautel et al. 2008; Thomspon 2004), and rates of alcohol or drug problems significantly exceeded rates found in matched housed samples (Toro \& Goldstein, 2000). Substance use is associated in YEH with increased risk for HIV infection (Nyamathi et al. 2010; Beech, Myers, Beech \& Kernick 2003; Wang, Matthew, Chiu, Yan \& Bellamy, 2007; 
Bailey, Camlin \& Ennet, 1998), suicide attempts (Salomonsen-Sautel et al. 2008; Kidd \& Carroll, 2007; Greene \& Ringwalt, 1996) and prostitution (Heerde \& Hemphill 2016; DeBeck, Shannon, Wood, Li, Montaner \& Kerr, 2007; Kipke, Montgomery \& MacKenzie, 1993). Therefore, it is important to understand the risk for frequent substance use among this group, as this can help inform the design of early prevention and intervention programs. This paper examines risk and protective factors for the frequency of substance use among YEH.

In a review of risk and protective factors for alcohol and drug problems in adolescence, Hawkins and colleagues (1992) defined risk factors as individual, contextual, and interpersonal factors that increase the probability that a given individual will develop substance problems. Protective factors, on the other hand, either reduce the likelihood of exposure to risk factors or buffer the negative impact of these factors (Hawkins et al., 1992; Rutter, 1985). Below, we apply these definitions to correlates of substance use often found among YEH. This conceptualization reveals that youth in these circumstances face multiple risk factors at each level, and homelessness itself may mitigate the benefit of some protective factors discussed in the literature.

\section{Individual Risk Factors}

Individual factors such as emotional distress, sensation seeking, and involvement in delinquent activities have long been shown to be strongly associated with substance use in non-homeless youth (Kilpatrick, Acierno, Saunders, Resnick, Best \& Shnurr, 2000; Baker \& Yardley, 2002; Colder, Campbell, Ruel, Richardson, \& Flay, 2002; Loeber, 1988; Whitmore et al., 1997). Both the self-medication hypothesis (Khantzian, 1985) and social learning theories (Jessor \& Jessor, 1973) would hypothesize these individual factors to be strong determinants of substance use in YEH. For example, studies of this population have found associations between substance use (especially frequent use) and suicide attempts, depression, and poor physical and emotional well-being, sensation seeking, delinquency, and having experienced violence or abuse (Salomonsen-Sautel et al. 2008; Nyamathi et al. 2010; Werb et al. 2015; Petering 2016; Fielding \& Forchuk 2013). These studies included youth of wide age ranges (e.g., 14-26, 15-25 years old) and addressed disparate research questions. Older and younger participants were infrequently disaggregated; when this was done (Salomonsen-Sautel et al. 2008), a few significant differences between the groups emerged but many correlates of greater substance use (regarding frequency and types used) were the same. Rationales for how particular individual risk factors contributed to substance use were often only implicit, but invoked previous trauma (e.g., abuse, loss, stigma), which could be consistent with self-medication. Some authors specifically noted the potential for these factors to interact (Fielding and Forchuk 2013).

\section{Contextual and Interpersonal Risk Factors}

While individual factors certainly contribute to substance use among youth, Hawkins and colleagues (1992) also crucially highlighted contextual and interpersonal risk factors. These are collapsed into one category in this section, primarily to emphasize the most important aspect such risk factors share: a focus on influences that transcend the individual. These risks may, for example, constitute a background that informs and constrains choices, dispositions and behavior, or they may account for the contingent and interactive nature of 
environments and relationships that facilitate or reduce substance use. These considerations may be particularly important for adolescents, given the salience of family and peers at this life stage. Making conceptual space for these influences is therefore essential, and enables a more nuanced analysis. Whether the factors subsumed in this compound category (e.g., exposure to violence, parental substance use) should most precisely be considered "contextual" or "interpersonal" is less important, from a clinical perspective, than acknowledging that they represent external conditions and forces that young people may have limited ability to alter by themselves.

Though homelessness is often treated as an individual characteristic (e.g., length of time homeless), living without a home frequently creates persistent stress and instability, engendered by the struggle to find accommodation, generate income, obtain sufficient food and remain safe. Hence, homelessness may more appropriately be seen as a context, given its wide-ranging potential impact on behavior and experience. Studies have shown that residential instability and the duration of homelessness are associated with increased risk of alcohol and drug abuse (Milburn et al. 2012; Parriott \& Auerswald 2009; Rosenthal, Mallett, Milburn, Rotheram-Borus 2008; Robertson \& Toro, 1999). In addition, living on the street confers a high risk of violence and victimization. For instance, among a sample of $601 \mathrm{YEH}$ recruited from Los Angeles, Denver and Austin, 51.6\% reported being physically assaulted, $24.5 \%$ reported being robbed, and $20.8 \%$ reported sexual assault; $28 \%$ experienced multiple types of such street victimization. In a hierarchical logistical regression model, each additional type of victimization significantly increased the likelihood of meeting criteria for substance use disorder by 90\% (Bender, Brown, Thompson, Ferguson, Langenderfer 2015).

Experiencing violence is not confined to street environments, however; it often precedes homelessness as well. In Strack et al.'s study of youth residing in group homes, a third of respondents had left home because of physical, verbal or sexual abuse (Strack, Anderson, Graham, Tomoyasu, 2007). Further, Bender et al. (2015) report that $88.7 \%, 79.9 \%$, and $33.6 \%$ of their sample had experienced childhood emotional, physical, and sexual abuse, respectively. Other contextual and interpersonal factors can also stem from families of origin. For example, a disproportionate number of youth living on the street have a substance abusing parent (Strack, Anderson, Graham, Tomoyasu, 2007; Ginzler, Cochran, DomenechRodriguez, Cauce \& Whitbeck, 2003; Cauce, Paradise, Ginzler, Embry, Morgan, Lohr \& Theofelis, 2000), a known etiological factor for youth substance use (Boyd et al. 2014; Johnson \& Leff, 1999). Indeed, among a sample of 684 YEH recruited from eight US cities, for younger (age 14-17) and older (age 18-24) participants alike, having a family history of a substance use problem and using substances with a parent were both significantly associated with recent substance use (Salmonsen-Sautel et al. 2008).

Peers' influence on adolescent substance use has been well-documented (Barman-Adhikari et al. 2017; Melander, Tyler \& Schmitz 2016; Andrews, Tildesley, Hops, \& Li, 2002;

Hawkins et al., 1992). For YEH, affiliation with deviant peers and involvement in drug-using social networks have been shown to be strong predictors of alcohol and drug use (Johnson, Whitbeck \& Hoyt, 2005; Rice, Milburn, Rotheram-Borus, Mallett, \& Rosenthal, 2005; McMorris, Tyler, Whitbeck, \& Hoyt, 2002). However, other aspects of peer relationships have rarely been considered. For instance, to date, stress related to peer interactions has not 
been examined as a risk factor, even though stress has long been known to correlate with substance use in many populations (Brady \& Sinha 2005; Bray, Fairbank \& Marsden 1999; Wills 1986). Overall, with potential exposure to multiple risk factors, YEH may be especially vulnerable to frequent substance use.

\section{Protective Factors}

Along with risk factors, studies have also explored skills, experiences, and characteristics associated with lower levels of substance use in YEH. Though variously defined and measured, the literature suggests that a greater degree of parental or adult caring and involvement is protective for adolescents (Saewyc \& Edinburgh 2010; Solorio, Rosenthal, Milburn, Weiss, Batterham, Gandara \& Rotheram-Borus; 2008; Bousman et al., 2005). Among a sample of 13-24 year olds without stable housing in Los Angeles, for instance, those who reported the perception that at least one family member would object to medically-unauthorized use of prescription drugs were significantly less to engage in this behavior (Barman-Adhikari et al. 2017). Unfortunately, many YEH do not have adults in their lives to provide this protective influence. Other factors that have been found protective against substance use in housed youth include: involvement in clubs or organizations, ability to set goals, decision making skills, valuing one's health, and personal resourcefulness (Fisher, Eke, Cance, Hawkins \& Lam, 2008; Gogineni, Stein, \& Friedman, 2001; Rutter, 1985; Taylor, Lydon, Bougie, \& Johannesen, 2004). This study will examine whether these other factors might also prove protective among YEH.

The current study examines individual, contextual, and interpersonal risk factors, as well as protective factors associated with varying frequencies of substance use in YEH. To date, very few studies (Bousman et al., 2005; Baron 1999) have systematically examined each factor in a large diverse sample. We hypothesized that the frequency of a youth's substance use would be positively associated with individual, contextual, and interpersonal risk factors. In contrast, protective factors would be negatively associated with substance use frequency.

\section{Method}

Sample

A total of 474 participants between the ages of 13 and 24 were recruited over a 1.5 year period (2004-05) from nine agencies that serve youth experiencing homelessness (including those who had run away) and unstable housing in Los Angeles. Agencies included drop-in centers (i.e., agencies where youth living on the street could receive a meal and other services) and shelters (i.e., agencies where youth could be housed for a night). Inclusion criteria were receiving services at a participating agency and speaking English. Youth were recruited to participate in a study of an HIV prevention program. The current study utilizes data collected prior to participants' involvement in any intervention activities.

\section{Procedures}

All procedures and forms were reviewed and approved by the UCLA Institutional Review Board. Youth provided informed consent; for minor youth a waiver of parental consent based on Federal Rule 45 CFR 46.408(c) was obtained. Although this study relied on 
computer-assisted structured interviewing to ensure standardization of assessment, resource constraints precluded the ideal of adding audio. This, coupled with the desire to include participants of all literacy levels, led to the utilization of interviewers to read the questions. Recognizing the delicacy of obtaining sensitive data in a face-to-face format, interviewers underwent 4-6 weeks of training in both research methods and subject area (ethics, rapport building and non-judgmental interaction with adolescents, collecting accurate data, research protocol, emergency procedures, adolescent development, social determinants of health, homelessness, general STI/HIV information). Assessments were conducted in English in private settings in community sites and community-based organizations, and lasted 1.5 hours. Participants received $\$ 20$ as compensation for their time.

\section{Measures}

Substance use.-Substance use was assessed using items adapted from the NIDA National Household Survey (1991), also used in prior studies with YEH (Lightfoot, Stein, Tevendale, \& Preston, 2011). We assessed frequency of use (e.g., how many days over the prior 3 months) of: alcohol; marijuana; non-prescribed sedatives, tranquilizers, antidepressants; non-prescribed painkillers, opiates; non-prescribed antipsychotic, moodregulating drugs, hallucinogens; designer or club drugs; inhaled or huffed drugs; stimulants or uppers; cocaine or crack; heroin; speedballs; and non-prescribed methadone. Based on responses to these questions, participants were classified into three categories describing the frequency of recent (past 3 months) substance use: 1) abstinent-no alcohol or substance use; 2) occasional/regular — alcohol use less than once a day and uses other drugs fewer than three times a week (less than daily use of alcohol and nonregular use of other drugs); and 3) frequent - alcohol use of once a day or uses other drugs three times a week or more (daily use of alcohol and regular use of other drugs). We maintained the analytic parsimony of 3 categories, but termed the middle group "occasional/regular" to recognize that it can include youth approaching frequent use of alcohol and other drugs.

\section{Individual Risk Factors}

Psychological Distress.-The Brief Symptom Inventory (BSI; Derogatis \& Melisaratos, 1993 ) is a 53-item multidimensional symptom inventory designed to assess symptomatic psychological distress. Respondents were asked to indicate the degree to which specific symptoms bothered them 5 -point scale $(1=$ not at all to $5=$ extremely). The Global Severity Index was utilized for the current study ( $a=0.96)$.

Delinquency.-Delinquency was assessed using an index of conduct disorder symptoms as defined by the DSM IV (American Psychiatric Association 2000; Rotheram-Borus et al., 1995). Respondents were asked if they had engaged, during the past year, in any of fifteen specific delinquent acts. Affirmative responses were summed to form a total score of conduct problems.

Sensation Seeking.-The Brief Sensation Seeking Scale (BSS) is an 8-item measure that assesses tendency to pursue varied, novel, and exciting experiences (Hoyle, Stephenson, Palmgreen, Lorch, \& Donohew, 2002). Participants indicated responses to items (e.g., I would love to have new and exciting experiences, even if they are illegal) on a 5-point scale 
( $1=$ strongly disagree to $5=$ strongly agree). The average of the eight items was calculated, with higher scores indicating a greater tendency toward sensation seeking $(a=0.73)$.

\section{Contextual and Interpersonal Risk Factors}

Homelessness.-Participants were asked to indicate the places they lived in the previous 3 months, as well as the total time they had ever experienced homelessness or away from home as a runaway. Formative work (focus groups with youth and discussions with agency staff) led to the development of an item with response options that grouped unstable housing with homelessness, as the intent of the agencies was to provide housing services for all youth in need. Thus, youth could be classified as "homeless only" (living only in a shelter, hotel, motel, single-room occupancy or youth hostel, friend's home, street, squat, abandoned building, or automobile), "housed only" (living only in their own apartment, room or house, parent's home, other relative's home, foster family home, or group home), or "homeless and housed" (indicating periods of both homelessness and being housed).

Exposure to Violence.-Exposure was assessed with six items that covered experiences such as witnessing another person being killed, another person being physically attacked, or someone being sexually assaulted (Kipke, Simon, Montgomery, Unger, \& Iversen, 1997). Outcome was dichotomized such that participants were classified as either "exposed" or "not exposed." An affirmative response to any item was sufficient to classify a participant as exposed.

Mother's education.-As a marker for socioeconomic status, youth reported their mother's highest level of education. For this question, participants were allowed to answer for whomever they considered their mother, biological or not.

Parental Substance Use.-Participants indicated whether or not their parent used alcohol or substances in the home. Again, determination of "parent" was at the participants' discretion.

Stressors.-The Major Life Events Scale addresses major life events specific to homeless youth (Unger, Kipke, Simon, Johnson, Montgomery, \& Iverson, 1998). Participants were asked whether each life event had happened to them within the past 3 months using a dichotomous rating scale, and if so, youth were asked to rate the event as not stressful, somewhat stressful, or very stressful. The measure contains 3 subscales: 1) 15-item homeless-related stress (e.g., problems finding a safe place to sleep), 2) 10-item familyrelated stress (e.g., death of a family member), and 3) 4-item peer-related stress (e.g., conflict with a lover/close friend). When a youth indicated that one or more problems in a subscale were somewhat or very stressful, the youth was coded as having experienced stress in that area ( stress $=1$, no stress $=0$ ).

\section{Protective Factors}

Involvement in organizations.-Participants were asked to indicate which of 10 agencies in the local area serving YEH they had received services from in the previous 3 
months. The total number of agencies accessed was calculated. In addition, participants reported how many hours in an average week they spent in clubs or organizations.

Goal Setting and Decision Making Skills.-The Goal Setting Skills scale (Hansen, 1992) is comprised of six items (e.g., When I set a goal, I think about what I need to do to achieve that goal) that assess ability to set goals and tendency to pursue goals $(a=0.82)$. The Decision Making Skills scale (Hansen, 1992) is comprised of four items (e.g., How often do you stop to think about options before you make a decision?) that assess the frequency with which participants consider options and possible consequences before making a decision, and their global assessment of whether they make good decisions ( $a=$ 0.70). Items in both scales are scored using a four point Likert scale $(1=$ Never to $4=$ All the time), with higher scores indicating stronger skills. The numeric outcomes from each scale were averaged, resulting in a single score.

Health as a Value.-The extent to which participants value their health was assessed with a four item measure (e.g., I am willing to make sacrifice to be healthy; Ritt-Olson et al., 2004). Items are rated on four point Likert-type scale $(1=$ strongly disagree, $4=$ strongly agree). The items were averaged together with higher scores indicating greater valuing of health $(a=0.69)$.

\section{Statistical analysis}

Demographics, risk, and protective factors were examined as potential predictors of substance use frequency. We first compared the predictive measures across the three substance use categories, using simple bivariate methods: Chi-square tests of independence for dummy and categorical measures, and one-way ANOVA tests of equality of means for the continuous measures. We then performed ordered logistic regressions to estimate the effects of the hypothesized predictor variables on the trichotomous outcome (abstinence, occasional/regular or frequent) of frequency of substance use. Use of this statistical method assumes that the odds ratio for being a frequent substance user (vs. being abstinent or an occasional/regular user) is the same as that for being a frequent or occasional/regular user (vs. being abstinent). This proportional odds assumption was tested in our analyses, and in none of the tests was the assumption rejected. Odds ratio estimates from the models can be interpreted as the effect of a one-unit change in a predictor on the odds of a higher level of substance use, when all other variables in the model are held constant.

We examined the relationship between each predictor and substance use individually, controlling for demographic characteristics. In addition, we ran models (not shown) in which all variables in one category (e.g., individual risk factors) were entered simultaneously, to confirm that the measures we used contributed significantly and independently to the outcome. We then estimated a multivariate model of substance use in which all hypothesized predictors were included at once.

For the scale variables (BSI global severity index, brief sensation seeking score, goal setting, decision making, and commitment to health) we standardized before estimating the regression models, so that effect size estimates would be in easily interpretable units. That is, we estimated the impact of a one standard deviation (1-SD) change in these scale variables. 
For example, 1-SD change in the BSI global score would be an increase from the mean score of 1.8 to a score of 2.4 .

\section{Results}

As shown in Table 1, youth were a mean age of 19.4 years (S.D. $=2.6)$, mostly male $(68 \%)$, and racial/ethnic minority (54\%). Over half of the sample (57.6\%) had experienced periods of homelessness and being housed in the preceding three months, while $35.5 \%$ had not been housed at all. Youth had experienced over two years of homelessness on average and most $(83 \%)$ reported stress associated with this. Well over half reported exposure to parental alcohol or drug use (65\%), violence (72\%), and family- or peer-related stress (both 59\%).

Youth reported high levels of alcohol and drug use, with $85 \%$ reporting any use and $32 \%$ reporting frequent use (see Table 1). On average, youth used alcohol 11 out of the prior 90 days, marijuana 23 of those days, and hard drugs 22 days. Compared to occasional/regular users, frequent users reported nearly four times the alcohol use, over eight times the marijuana use, and nearly twenty times the hard drug use. Greater frequency of use was linked to all the individual risk factors (BSI global $\mathrm{F}=3.5, \mathrm{p}=0.030$; delinquency $\mathrm{F}=7.9, \mathrm{p}<$. 001; brief sensation seeking $\mathrm{F}=30.1, \mathrm{p}<.001$ ), and also to the severity of homelessness (months runaway: $\mathrm{F}=9.2, \mathrm{p}<.001$; housing category: $\mathrm{X}^{2}=22.3, \mathrm{p}<.001$; experienced homeless-related stress: $\left.X^{2}=9.1, p=0.011\right)$. Frequent users were also more likely to have been exposed to parental substance use $\left(X^{2}=6.3, p=0.043\right)$ and violence $\left(X^{2}=15.4, p<.001\right)$, experienced peer stress $\left(\mathrm{X}^{2}=8.5, \mathrm{p}=0.014\right)$, and to have accessed services at more agencies $(\mathrm{F}=4.1, \mathrm{p}=0.018)$. Those who used substances more often scored lower in goal setting $(\mathrm{F}=7.4, \mathrm{p}=0.001)$, decision making $(\mathrm{F}=4.7, \mathrm{p}=0.009)$, and health value $(\mathrm{F}=7.4, \mathrm{p}=0.001)$.

Analysis of predictors individually indicated that all hypothesized predictors, with the exception of family-related stress, maintained a statistically significant relationship with substance use. However, as shown in Table 2, when all variables were included in the model, only delinquency, sensation-seeking, and housing status persisted in predicting more frequent substance use. In terms of individual risk factors, increasing the number of delinquent acts was significantly associated with increased odds of more frequent substance use, while a 1-SD increase in sensation seeking increased the odds of more frequent substance use by $60 \%$. Regarding the contextual risk factor of housing status, compared to youth who were consistently housed, youth who were continuously homeless had four times greater odds and youth who moved between homeless and housed status had almost three times greater odds of engaging in more frequent substance use. Interestingly, one contextual risk factor, mother's education, was found to be significant in only a protective direction; in comparison to having a mother with some college education, youth reporting their mother's education as unknown or less than a high school graduation had lower odds of frequent substance use. Among protective factors tested in the multivariate model, only the relationship between substance use and connection to organizations persists, with an additional hour in a club or organization being linked to decreased odds of frequent substance use. 


\section{Discussion}

YEH reported a disturbingly high frequency of substance use, with almost a third of the sample qualifying as frequent substance users. High frequency of substance use was related to a number of risk factors in bivariate analysis. As expected, youth who frequently used substances were more likely to report emotional distress, delinquency, and exhibit a tendency toward sensation-seeking. They had also been more consistently homeless, spent more time homeless, and experienced greater contextual stressors. In addition, those who reported a higher frequency of substance use were less likely to possess the personal assets that would contribute to positive coping and outcomes, such as goal setting and decision making skills, and were less likely to endorse health as a value.

The relationships between substance use frequency and risk factors were maintained in univariate regression analysis. The frequency of YEH's substance use was predicted by negative outcomes, such as higher emotional distress and delinquency. This cluster of behaviors and experiences may negatively impact their chances for future success and wellbeing. For example, high levels of substance use and delinquency may increase the likelihood of unemployment and incarceration, which suggests the importance of intervening to treat and prevent frequent substance use among this population.

Interestingly, whereas greater contact with homeless service agencies was hypothesized to be protective for youth, accessing services through a greater number of local agencies was actually found to be related to more frequent substance use. One explanation for this may be that, among youth who are willing to use such agencies, those facing the greatest struggles (including with substance use issues) engage in more support- and service-seeking. While issues of quality or adequacy of services lie beyond the scope of this paper, it is heartening to find that youth with these pressing needs may be most likely to connect with institutions that aim to help them.

Factors in the multivariate analysis that best predicted frequency of substance use in this population were delinquency, sensation seeking, homelessness experience, mother's education, and number of hours spent in organizations. While other variables were significant individually, their effect diminished in the multivariate model. Among individual factors, delinquency and sensation seeking predicted frequent substance use. Notably, these variables are important predictors of substance use among both housed young people and YEH, suggesting a powerful relationship that manifests in various contexts. Not surprisingly, however, context is also important: those youth who were chronically homeless, with no periods of being housed, were at increased risk for being frequent substance users. This study supports other research that suggests housing instability is a significant risk factor for substance use (Clatts, Goldsamt, Yi, \& Gwadz, 2005; Sibthorpe, Drinkwater, Gardner \& Bammer, 1995; Robertson \& Toro, 1999).

In addition, having a mother with some college education increased the odds of more frequent substance use. While higher SES has been shown to be significantly related to adolescent substance use in other studies (Hanson and Chen, 2007; Monuteaux, Wilens, \& Biederman, 2007), it is not clear why this might be the case for YEH. Youth from families of 
higher socioeconomic status might be expected to have access to treatment for substance use that was frequent and problematic. However, if treatment failed, the continued conflict in these families might have resulted in the youth running away or being asked to leave. Hence, YEH from families of higher socioeconomic status may represent those youth who have had ongoing substance use problems. Future research is needed to further explicate the relationship between socioeconomic status, substance use, and reasons for youth experiencing homelessness.

The only protective factor found significant in the multivariate model was a greater number of hours spent at organizations dedicated to helping youth who had run away or were homeless. This implies that connection with support—even if not provided by parents — can help reduce substance use for young people. Nonetheless, it must be noted that two-thirds of this sample did not qualify as "frequent" substance users, despite their homeless or marginally housed status. This suggests the existence of additional factors, not adequately captured in this study, that protect these highly vulnerable youth.

Nonetheless, the current study suggests that housing young people and providing services to curb delinquency are important factors in protecting youth from becoming frequent substance users. Further, skills and attitudes found to be protective in other contexts were not significant predictors in our model, which calls attention to an area that merits more research. It is possible that experiences with resource scarcity and/or perceptions of diminished personal agency associated with life on the street may mitigate the importance of factors that protect housed youth. It is also possible that other factors acquire new importance for this population; for example, scholars are increasingly turning attention to "resilience" (Kidd \& Shahar 2008; Zerger et al. 2008; Saewyc \& Edinburgh 2010; Oppong \& Meyer-Witz 2015; Brooks et al. 2016), a complex construct that often involves selfesteem, social connectedness, and hope/optimism. In addition, a recent systematic review (Conley \& Evans 2017) suggests spirituality and creativity may be relevant components of resilience for youth. All of these domains merit exploration with YEH.

The current study has the limitation of being cross-sectional. We are unable to determine causation between the variables under investigation. Additionally, the current study included only youth who were receiving services at a drop-in center or shelter for YEH, somewhat limiting which youth are included in this study. However, past research indicated that 6080\% of YEH in Los Angeles accessed services at such centers (Milburn et al. 2006) suggesting that our study sample may in fact include a broad sample. Finally, though mindful of the potential for recall bias in querying substance use over three months, other study-related considerations (i.e., intervention follow-up period) led to selecting this period.

The linkages between homelessness, substance use, delinquency, experiences of violence, and poor mental health among youth are complex and often have the effect of constraining their future opportunities. Hence, early intervention and treatment for frequent substance use for this group is imperative, and likely to lead to improved well-being and quality of life. In addition, the current study suggests that housing young people and providing services to curb delinquency are important factors in protecting youth from becoming frequent 
substance users. Future research must focus on building models of resilience and developing the measures that adequately capture those factors that are protective for homeless youth.

\section{Acknowledgments:}

The authors thank the youth and the youth-serving agencies that made this study possible, as well as the many research staff members involved in data collection.

\section{References}

American Psychiatric Association. (2000). Diagnostic and statistical manual of mental disorders (4th ed.) Washington DC: Author.

Andrews JA, Tildesley E, Hops H, \& Li F (2002). The influence of peers on young adult substance use. Health Psychology, 21, 349-357. [PubMed: 12090677]

Bailey SL, Camlin CS, \& Ennett ST (1998). Substance use and risky sexual behavior among homeless and runaway youth. Journal of Adolescent Health, 23, 378-388. [PubMed: 9870332]

Baker JR, \& Yardley JK (2002). Moderating effect of gender on the relationship between sensation seeking-impulsivity and substance use in adolescents. Journal of Child \& Adolescent Substance Abuse, 12(1), 27-43.

Barman-Adhikari A, Al Tayyib A, Begun S, Bowen E, \& Rice E (2017). Descriptive and injunctive network norms associated with nonmedical use of prescription drugs among homeless youth. Addict Behav, 64, 70-7. [PubMed: 27563741]

Baron S (1999). Street youths and substance use. Youth \& Society, 31(1), 3-26.

Beech BM, Myers L, Beech DJ \& Kernick NS (2003). Human immunodeficiency syndrome and hepatitis B and C infections among homeless adolescents. Seminars in Pediatric Infectious Diseases, 14(1), 12-19. [PubMed: 12748917]

Bender K, Brown SM, Thompson SJ, Ferguson KM, \& Langenderfer. L (2015). Multiple Victimizations Before and After Leaving Home Associated with PTSD, Depression, and Substance Use Disorder Among Homeless Youth. Child Maltreatment, 20(2), 115-24. [PubMed: 25510502]

Bousman CA, Blumberg EJ, Shillington AM, Hovell MF, Ji M, Lehman S, et al. (2005). Predictors of substance use among homeless youth in San Diego. Addictive Behaviors, 30(6), 1100-1110. [PubMed: 15925120]

Brady KT \& Sinha R (2005). Co-Occurring Mental and Substance Use Disorders: The Neurobiological Effects of Chronic Stress. American Journal of Psychiatry 162(8): 1483-1493. [PubMed: 16055769]

Bray RM, Fairbank JA, \& Marsden ME (1999). Stress and Substance Use Among Military Women and Men. The American Journal of Drug and Alcohol Abuse 25(2): 239-256. [PubMed: 10395158]

Brooks MJ, Marshal MP, McCauley HL, Douaihy A, \& Miller E (2016). The Relationship Between Hope and Adolescent Likelihood to Endorse Substance Use Behaviors in a Sample of Marginalized Youth. Subst Use Misuse 51(13), 1815-9. [PubMed: 27556872]

Boyd CJ, McCabe SE, Cranford J (2014). Adolescent substance use and the identification of subgroups. Drug \& Alcohol Dependence, 140: e17-e18.

Cauce Ana Mari, Matthew Paradise, Joshua Aaron Ginzler, Lara Embry, Charles J. Morgan, Yvette Lohr, and Jim Theofelis. (2000). "The Characteristics and Mental Health of Homeless Adolescents.” Journal of Emotional and Behavioral Disorders 8 (4):230-9.

Clatts MC, Goldsamt L, Yi H, \& Gwadz MV. (2005). Homelessness and drug abuse among young men who have sex with men in New York City: a preliminary epidemiological trajectory. Journal of Adolescence, 28, 201-14. [PubMed: 15878043]

Colder CR, Campbell RT, Ruel E, Richardson JL, \& Flay BR (2002). A finite mixture model of growth trajectories of adolescent alcohol use: Predictors and consequences. Journal of Consulting and Clinical Psychology, 70(4), 976-985. [PubMed: 12182281]

Cronley C \& Evans R (2017). Studies of resilience among youth experiencing homelessness: A systematic review. Journal of Human Behavior in the Social Environment 27(4): 291-310. 
Derogatis LR, \& Melisaratos N (1993). The Brief Symptom Inventory: An introductory report. Psychological Medicine, 13, 595-605.

DeBeck K, Shannon K, Wood E, Li K, Montaner J, \& Kerr T (2007). Income generating activities of people who inject drugs. Drug Alcohol Depend 91(1), 50-56. [PubMed: 17561355]

De Rosa CJ, Montgomery SB, Kipke MD, Iverson E, Ma JL, \& Unger JB (1999). Service utilization among homeless and runaway youth in Los Angeles, California: rates and reasons. Journal of Adolescent Health, 24(6), 449-458. [PubMed: 10401975]

Fielding K, \& Forchuk C (2013). Exploring the factors associated with youth homelessness and arrests. J Child Adolesc Psychiatr Nurs, 26(4), 225-33. [PubMed: 24118353]

Fisher HH, Eke AN, Cance JD, Hawkins SR, \& Lam WK (2008). Correlates of HIV-related risk behaviors in African American adolescents from substance-using families: patterns of adolescentlevel factors associated with sexual experience and substance use. J Adolesc Health, 42(2), 161-9. [PubMed: 18207094]

Ginzler JA, Cochran BN, Domenech-Rodriguez M, Cauce AM, \& Whitbeck LB (2003). Sequential progression of substance use among homeless youth: an empirical investigation of the gateway theory. Subst Use Misuse 38 (3-6), 725-58. [PubMed: 12747403]

Gogineni A, Stein MD, \& Friedman PD (2001). Social relationships and intravenous drug use among methadone maintenance patients. Drug and Alcohol Dependence, 64, 47-53. [PubMed: 11470340]

Greene JM, \& Ringwalt CL (1996). Youth and familial substance use's association with suicide attempts among runaway and homeless youth. Substance Use and Misuse, 31, 1041-1058. [PubMed: 8806167]

Hansen WB (1992). School-based substance abuse prevention: a review of the state of the art in curriculum, 1980-1990. Health Education Research, 7, 403-420. [PubMed: 10171672]

Hanson MD, \& Chen E (2007). Socioeconomic status and substance use behaviors in adolescents: the role of family resources versus family social status. Journal of Health Psychology, 12, 32-35. [PubMed: 17158838]

Hawkins JD, Catalano RF, \& Miller JY (1992). Risk and protective factors for alcohol and other drug problems in adolescence and early adulthood: Implications for substance abuse prevention. Psychological Bulletin, 112(1), 64-105. [PubMed: 1529040]

Heerde JA, \& Hemphill SA (2016). Sexual Risk Behaviors, Sexual Offenses, and Sexual Victimization Among Homeless Youth: A Systematic Review of Associations With Substance Use. Trauma Violence Abuse, 17(5), 468-89. [PubMed: 25985990]

Hoyle RH, Stephenson MT, Palmgreen P, Lorch EP, \& Donohew RL (2002). Reliability and validity of a brief measure of sensation seeking. Personality and Individual Differences, 32, 401-414.

Jessor R, \& Jessor SL (1973). A social psychology of marijuana use: Longitudinal studies of high school and college youth. Journal of Personality and Social Psychology, 26(1), 1-15. [PubMed: 4695484]

Johnson JL, \& Leff M (1999). Children of substance abusers: Overview of research findings. Pediatrics, 103, 1085-1099. [PubMed: 10224196]

Johnson KD, Whitbeck LB \& Hoyt DR (2005). Substance Abuse Disorders Among Homeless and Runaway Adolescents. J Drug Issues 35(4), 799-816. [PubMed: 21533015]

Kidd SA, \& Carroll MR (2007). Coping and suicidality among homeless youth. J Adolesc 30(2), 28396. [PubMed: 16631925]

Kidd S, \& Shahar G (2008). Resilience in homeless youth: the key role of self-esteem. Am J Orthopsychiatry 78(2),163-72. [PubMed: 18954180]

Kilpatrick DG, Acierno R, Saunders B, Resnick HS, Best CL \& Schnurr PP (2000). Risk factors for adolescent substance abuse and dependence: Data from a national sample. Journal of Consulting and Clinical Psychology, 68(1):19-30. [PubMed: 10710837]

Khantzian EJ (1985). The self-medication hypothesis of addictive disorders: Focus on heroin and cocaine dependence. American Journal of Psychiatry, 142(11), 1259-1264. [PubMed: 3904487]

Kipke MD, Montgomery S, \& MacKenzie RG (1993). Substance use among youth seen at a community-based health clinic. Journal of Adolescent Health, 14(4), 289-294. [PubMed: 8347640] 
Kipke MD, Simon TR, Montgomery SB, Unger JB, \& Iversen EF (1997). Homeless youth and their exposure to and involvement in violence while living on the streets. Journal of Adolescent Health, 20, 360-367. [PubMed: 9168383]

Lightfoot M, Stein JA, Tevendale H, Preston K (2011). Protective Factors Associated with Fewer Multiple Problem Behaviors Among Homeless/Runaway Youth. Journal of Clinical Child \& Adolescent Psychology 40(6), 878-889. [PubMed: 22023279]

Loeber R (1988). Natural histories of conduct problems, delinquency, and associated substance use: Evidence for development progressions. Advances in Clinical Child Psychology, 11, 73-124.

McMorris BJ, Tyler KA, Whitbeck LB, \& Hoyt DR (2002). Familial and "on-the-street" risk factors associated with alcohol use among homeless and runaway adolescents. Journal of Studies on Alcohol, 63(1), 34-43. [PubMed: 11925056]

McLellan AT, Luborsky L, Woody GE, \& O’Brien CP (1980). An Improved Diagnostic Evaluation Instrument for Substance Abuse Patients: The Addiction Severity Index. The Journal of Nervous and Mental Disease 168(1), 26-33. [PubMed: 7351540]

Melander LA, Tyler KA \& Schmitz RM (2016). An Inside Look at Homeless Youths' Social Networks: Perceptions of Substance Use Norms. Journal of Child \& Adolescent Substance Abuse, 25(1), 78-88. [PubMed: 26989340]

Milburn NG, Rotheram-Borus MJ, Rice E, Mallet S, \& Rosenthal D (2006). Cross-National Variations in Behavioral Profiles Among Homeless Youth. American Journal of Community Psychology, 37(1), 63. [PubMed: 16680537]

Milburn NG, Iribarren FJ, Rice E, Lightfoot M, Solorio R, Rotheram-Borus MJ, Demond, \&. et al. 2012 A Family Intervention to Reduce Sexual Risk Behavior, Substance Use, and Delinquency Among Newly Homeless Youth. Journal of Adolescent Health, 50, 358-64. [PubMed: 22443839]

Monuteaux MC, Wilens TE, \& Biederman J (2007). Does social class predict substance problems in young adults with ADHD? American Journal on Addictions, 16, 403-9. [PubMed: 17882612]

National Institute on Drug Abuse. (1991). National household survey on drug abuse: population estimates. (DHHS Publication No. ADM 92-1887). Washington, DC: U.S. Government Printing Office.

Nyamathi A, Hudson A, Greengold B, Slagle A, Marfisee M, Khalilifard F \& Leake B (2010). Correlates of Substance Use Severity Among Homeless Youth. Journal of Child and Adolescent Psychiatric Nursing 23(4), 214-22. [PubMed: 21073596]

Oppong Asante K, \& Meyer-Weitz A (2015). International note: association between perceived resilience and health risk behaviours in homeless youth. J Adolesc 39, 36-9. [PubMed: 25575268]

Parriott AM, \& Auerswald CL (2009). Incidence and Predictors of Onset of Injection Drug Use in a San Francisco Cohort of Homeless Youth. Substance Use \& Misuse 44(13), 1958-70. [PubMed: 20001291]

Petering R (2016). Sexual risk, substance use, mental health, and trauma experiences of gang-involved homeless youth. J Adolesc 48, 73-81. [PubMed: 26897432]

Rice E, Milburn NG, Rotheram-Borus MJ, Mallett S, \& Rosenthal D (2005). The effects of peer group network properties on drug use among homeless youth. American Behavioral Scientist, 48(8), 1102-1123. [PubMed: 20539820]

Ritt-Olson A, Milam J, Unger JB, Trinidad D, Teran L, Dent CW, \& Sussman S (2004). The protective influence of spirituality and "Health-as-a-Value" against monthly substance use among adolescents varying in risk. Journal of Adolescent Health, 34, 192-199. [PubMed: 14967342]

Robertson MJ, \& Toro PA (1999). Homeless youth: Research, intervention, and policy In Fosburg LB \& Dennis DL (Eds.), Practical lessons: The 1998 National Symposium on Homelessness Research (pp. 3-1:3-32). Washington, DC: U.S. Department of Housing and Urban Development and U.S. Department of Health and Human Services.

Rosenthal D, Mallett S, Milburn N, \& Rotheram-Borus MJ (2008). Drug use among homeless young people in Los Angeles and Melbourne. Journal of Adolescent Health, 43(3), 296-305. [PubMed: 18710685]

Rotheram-Borus MJ, Rosario M, Reid H, \& Koopman C (1995). Predicting patterns of sexual acts among homosexual and bisexual youths. American Journal of Psychiatry, 152(4), 588-95. [PubMed: 7694909] 
Rutter M (1985). Resilience in the face of adversity: Protective factors and resistance to psychiatric disorder. British Journal of Psychiatry, 147, 598-611. [PubMed: 3830321]

Saewyc EM, \& Edinburgh LD (2010). Restoring healthy developmental trajectories for sexually exploited young runaway girls: fostering protective factors and reducing risk behaviors. J Adolesc Health, 46(2), 180-8. [PubMed: 20113924]

Salomonsen-Sautel S, Van Leeuwen JM, Gilroy C, Boyle S, Malberg D, Hopfer C Correlates of Substance Use Among Homeless Youths in Eight Cities. The American Journal on Addictions, 17, 224-234. [PubMed: 18464000]

Sibthorpe B, Drinkwater J, Gardner K, \& Bammer G (1995). Drug use, binge drinking and attempted suicide among homeless and potentially homeless youth, Australian New Zealand Journal of Psychiatry, 29, 248-256. [PubMed: 7487787]

Solorio MR, Rosenthal D, Milburn NG, Weiss RE, Batterham PJ, Gandara M, \& Rotheram-Borus MJ (2008). Predictors of sexual risk behaviors among newly homeless youth: a longitudinal study. J Adolesc Health, 42(4), 401-9. [PubMed: 18346666]

Strack RW, Anderson KK, Graham CM, \& Tomoyasu N (2007). Race-gender Differences in Risk and Protective Factors among Youth in Residential Group Homes. Child and Adolescent Social Work Journal, 24(3), 261-83.

Taylor DM, Lydon JE, Bougie É, \& Johannesen K (2004). "Street kids": Towards an understanding of their motivational context. Revue canadienne des sciences du comportement [Canadian Journal of Behavioural Science], 36(1), 1-16.

Thompson SJ (2004). Risk/protective factors associated with substance use among runaway/homeless youth utilizing emergency shelter services nationwide. Subst Abus, 25(3), 13-26. [PubMed: 16150676]

Toro PA, \& Goldstein MS (2000 8). Outcomes among homeless and matched housed adolescents: A longitudinal comparison Paper presented at the 108th Annual Convention of American Psychological Association, Washington, DC.

Unger JB, Kipke MD, Simon TR, Johnson CJ, Montgomery SB, \& Inverson E (1998). Stress, coping and social support among homeless youth. Journal of Adolescent Research, 13, 134-157.

Wang MQ, Matthew RF, Chiu Yu-Wen, Yan Fang, \& Bellamy ND. (2007). Latent Model Analysis of Substance Use and HIV Risk Behaviors Among High-risk Minority Adults. Journal of Alcohol and Drug Education 51(4), 35-62.

Werb D, Richardson C, Buxton J, Shoveller J, Wood E, \& Kerr T (2015). Development of a brief substance use sensation seeking scale: validation and prediction of injection-related behaviors. AIDS Behav, 19(2), 352-61. [PubMed: 25119056]

Wills TA (1986). Stress and coping in early adolescence: Relationships to substance use in urban school samples. Health Psychology 5(6): 503-529. [PubMed: 3492372]

Whitmore EA, Mikulich SK, Thompson LL, Riggs PD, Aarons GA, \& Crowley TJ (1997). Influences on adolescent substance dependence: conduct disorder, depression, attention deficit hyperactivity disorder, and gender. Drug and Alcohol Dependence, 47, 87-97. [PubMed: 9298330]

Zerger S, Strehlow AJ \& Gundlapalli AV (2008). Homeless Young Adults and Behavioral Health: An Overview. American Behavioral Scientist, 51(6), 824-841. 


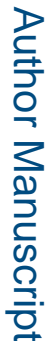

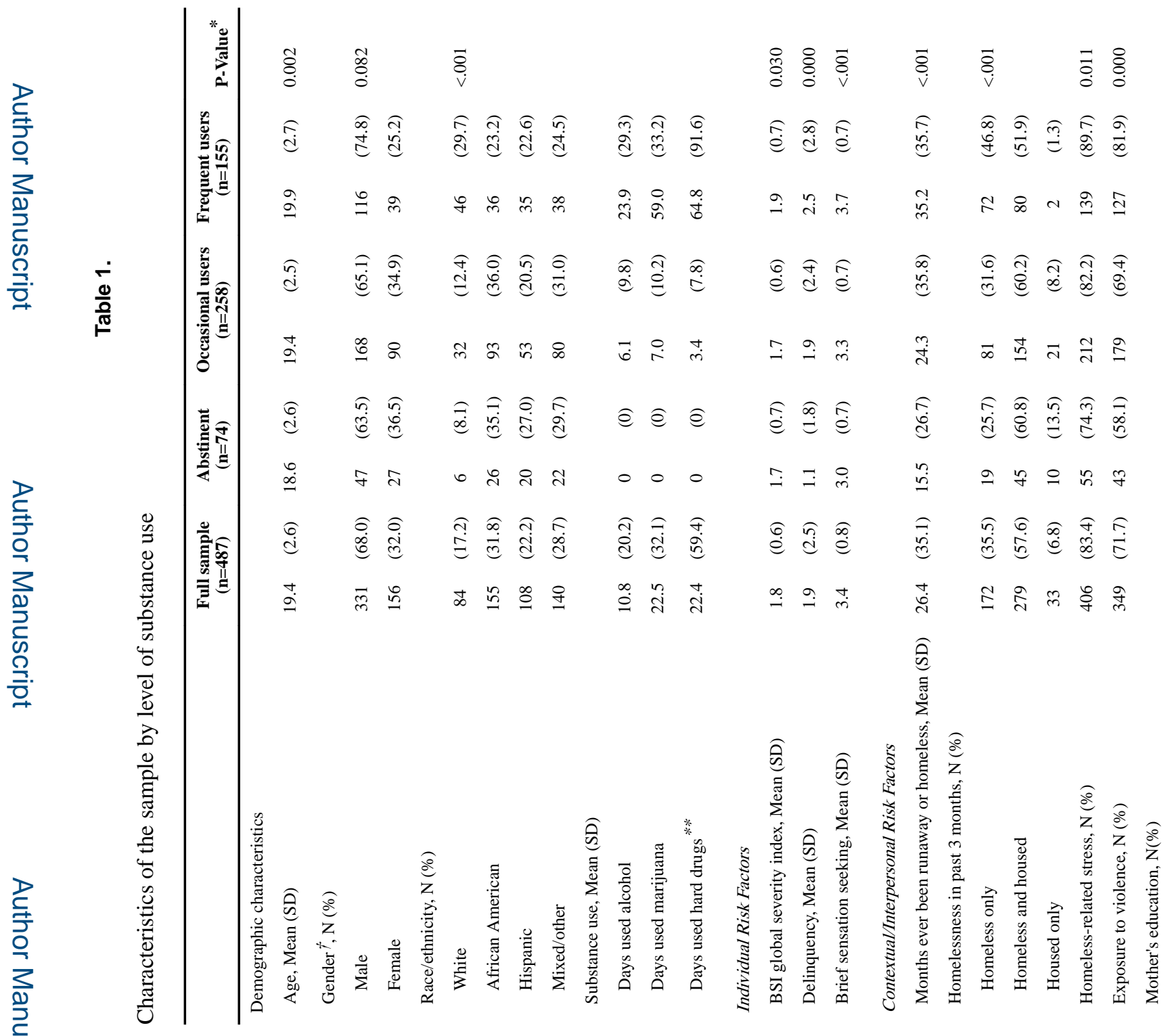


